\title{
PROPOSED EFFECTIVE WIDTH CRITERIA FOR SLAB DECK BRIDGES UNDER MILITARY TRACKED LOAD
}

\author{
BASSAM QASIM ABDULRAHMAN* \\ Dept. of Surveying, Darbandikhan Technical Institute, Sulaimani Polytechnic University, \\ Al-Sulaymania, Kurdistan Region-Iraq
}

(Accepted for Publication: December 8, 2020)

\begin{abstract}
For any slab deck bridge, the ultimate loading strength is obtained based on the distribution of that loading to a slab effective width that recommended in the adopted specifications. In this study, a simplified procedure with a design equation is presented. This procedure depends on the determination of the moments developed in a slab deck bridge and thus the slab effective width that loading is distributed to. The study employs the Iraqi military tracked load. The procedure applies to right, simply supported slab deck bridges with and without edge stiffening beams based on the aspect ratio that represents the ratio of the slab width to length. A 3D finite element analysis by a well-known programme ABAQUS was conducted to analyse the whole bridges and to give the values of moments that will be used in the derivation of an equation to calculating the slab effective width. Furthermore, a comparison between the effective width of this study and the AASHTO and LRFD specifications was conducted. It is found that this method gives some conservative results in comparison with AASHTO and LRFD standards because other standards have some limitations, besides not to take in consideration all the parameters required.
\end{abstract}

KEY WORDS : Slab bridges, Military load, Tracked load, Effective width

\section{INTRODUCTION}

A nalysis of bridges is complicated because of the variety in the bridge geometry, type of supports and the applied loading (Deng et al 2018). Experimental, analytical and more recently numerical studies have been proceeded to improve the techniques used in the analysis and design. Furthermore, they are also used to give more understanding to the structural behaviour of the bridges and to demonstrate the load-carrying capacity of the bridges under more loading. Unfortunately, these studies have not resulted in a realistic and simple procedure. Theoretical studies vary based on their assumptions. Analytical studies are not possible unless simplifications to the assumptions and reduction of the problem to a one that can be solved.
Loading distribution is the key element to the bridge engineers in the design and analysis of bridges because the slab in every bridge is designed for their loading (Drar et al 2016)]. Furthermore, it is also important to know the width of the slab which is effective in carrying the bridge loading. So, many studies were conducted to know this width as follows:

The basic concept of the effective width was first developed by Goldbeck and Smith (1916) and Goldbeck, A. T. (1917). They obtained the effective width from the stress distribution over the slab width. This width was attributed to the effective slab width as the effective action from the maximum stress distributed over the slab effective width equals the action resulting from the variable stresses over the slab entire width as explained in Figure 1. Generally, they considered the effective width as eighty per cent of the span length. 


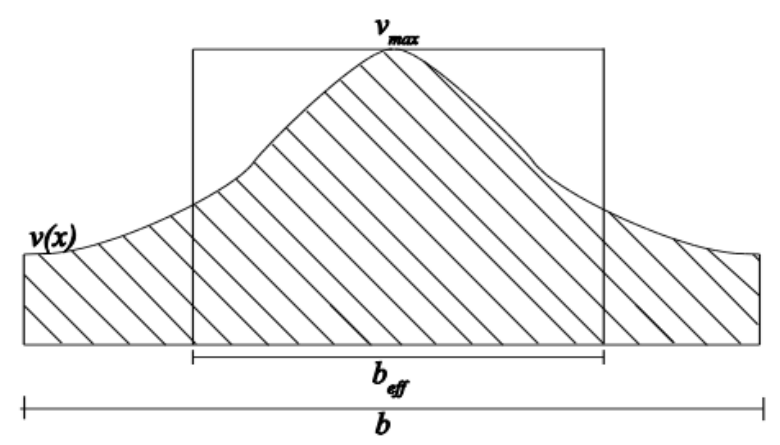

Fig. (1): Principle of effective width, $b_{\text {eff: }}$ the area underneath the curve of the shear stress over the width $b$ equals the area of the maximum shear stress over $b_{\text {eff }}$ [Goldbeck et al 1917]

Westergaard and Slater (1921) explained the theory of flexure of slabs and they recognised the effects due to the internal arching action. Their work was effective in the calculation of the flexural stresses in bridge slabs due to an applied wheel load based on the grillage analysis.
Later studies by Westergaard, H.M. (1930) on isotropic slab deck bridges with two opposite fixed edges prepared equations for calculating the effective slab width by considering the diameter of the contacting area in addition to the slab thickness and the distance from the loading to the supporting edge.

$$
\begin{gathered}
\mathrm{B}_{\mathrm{e}}=2 \mathrm{C}+1.4 \mathrm{~d} \\
\mathrm{~B}_{\mathrm{e}}=2 \mathrm{t}+1.4 \mathrm{~d} \ldots \ldots
\end{gathered}
$$

Where $\mathrm{C}$ is the diameter of the contact surface under the load, $\mathrm{d}$ is the distance from the load centre to the bridge support and $t$ is the thickness of the slab, all being expressed in feet and the greater value is used.

Further studies by Slater et al (1923) stated that the slab effective width depends on the loading type (concentrated or distributed with different directions) that causes the maximum moment in the slab to be distributed to that width and the ratio of the slab width to its span length.

The basic concept of the effective width was also developed by Johansen, K. W. [Johansen, K.W. 1932] who found that the effective width would be twice the span multiplied by $\sqrt{u}$. He also described the value of $u$ as the ratio of the transverse top steel reinforcement to the longitudinal bottom reinforcement.

Motarjemi and Van Horn (1969) introduced more realistic empirical rules for load distribution for bridges which were stated in AASHTO 1973.

Stanton, J. F. (1987) presented that the better distribution of loading can be obtained by treating as a triangular mode. The effective width must be twice that used in the rectangular diagram so that a given concentrated load will still lead to the same maximum response per unit width.

Warren and Malvar (1993) investigated the lateral distribution of the stresses resulted from wheel loads in the navy pier deck. They confirmed that the equivalent width for reinforced concrete slabs can often be doubled over current AASHTO values.

German Standards [DIN 1045] (2008) presented the load distribution under point, linear and rectangular loads. The effective width transversely to the spanning direction is calculated in accordance with table 1 . 
Table (1): Load Distribution Width for German standards (DIN 2008)

\begin{tabular}{|c|c|c|}
\hline Structural system & Load effective width (bm) & limits of validity \\
\hline$M_{f}$ & $b_{m}=b_{w}+2.5 x(1-x / l)$ & $0<x<l \quad b_{w}<0.8 l$ \\
\hline $\mathrm{M}_{\mathrm{f}}$ & $\begin{array}{l}b_{m}=b_{w}+1.5 x(1-x / l) \\
b_{m}=b_{w}+0.5 x(2-x / l)\end{array}$ & $\begin{array}{ll}0<x<l & b_{w}<0.8 l \\
0<x<l & b_{w}<0.8 l\end{array}$ \\
\hline $\mathrm{M}_{\mathrm{f}}$ & $b_{m}=b_{w}+x(1-x / l)$ & $0<x<l \quad b_{w}<0.8 l$ \\
\hline $\mathrm{X}$ & & \\
\hline
\end{tabular}

Where $b_{w}=$ load transmission width.

$\mathrm{b}_{\mathrm{m}}=$ Load effective width, $\mathrm{x}$ is the distance from the load centre to the nearest support.

For the calculations of the bending moment per unit width, the following formula should be applied:

$\mathrm{m}=\frac{\mathrm{M}}{\mathrm{b}_{\mathrm{m}}}$
Where $\mathrm{m}$ is the bending moment per unit width and $\mathrm{M}$ is the total bending moment in the slab.

For slabs exposed to a single concentrated load and supported on two opposite edges, the effective width was given by the Indian Road Congress [Indian Road Congress 2013] as:

$$
\mathrm{B}_{\mathrm{e}}=\mathrm{Kx}\left(1-\frac{\mathrm{x}}{\mathrm{L}}\right)+\mathrm{b}_{\mathrm{w}}
$$

Where $B_{e}$ is the slab effective width on which the load is applied, $\mathrm{L}$ is the effective span length, $\mathrm{x}$ is the distance from the load centre to nearest support, $b_{w}$ is the concentration area width of the load and $\mathrm{K}$ is a constant depends on the ratio $(B / L)$, where $B$ is the width of the slab.

The values of the constant $\mathrm{K}$ for different values of $(\mathrm{B} / \mathrm{L})$ ratio is presented in table 2 for simple and continuous support.

Table (2): Values of K Factor in Indian Road Congress [Indian Road Congress 2013]

\begin{tabular}{cccccc}
\hline $\mathbf{B} / \mathbf{L}$ & $\begin{array}{c}\mathrm{K} \text { for simply } \\
\text { supported slabs }\end{array}$ & $\begin{array}{c}\mathrm{K} \text { for continuous } \\
\text { slabs }\end{array}$ & $\mathbf{B} / \mathbf{L}$ & $\begin{array}{c}\mathbf{K} \text { for simply supported } \\
\text { slabs }\end{array}$ & $\mathbf{K}$ for continuous slabs \\
\hline 0.1 & 0.4 & 0.4 & 1.1 & 2.6 & 2.28 \\
\hline 0.2 & 0.8 & 0.8 & 1.2 & 2.64 & 2.36 \\
\hline 0.3 & 1.16 & 1.16 & 1.3 & 2.72 & 2.40 \\
\hline 0.4 & 1.48 & 1.44 & 1.4 & 2.80 & 2.48 \\
\hline 0.5 & 1.72 & 1.68 & 1.5 & 2.84 & 2.48 \\
\hline 0.6 & 1.96 & 1.84 & 1.6 & 2.88 & 2.56 \\
\hline 0.7 & 2.12 & 1.96 & 1.7 & 2.92 & 2.60 \\
\hline 0.8 & 2.24 & 2.08 & 1.8 & 2.96 & 2.60 \\
\hline 0.9 & 2.36 & 2.16 & 1.9 & 3.00 & 2.60 \\
\hline 1 & 2.48 & 2.24 & 2 and & 3.00 & \\
\hline
\end{tabular}


The American Association of State Highway and Transportation Officials (AASHTO) introduced a simple method depends on reducing the analysis of slab deck bridges to a beam with a width equals the equivalent width (AASHTO 2017).

$$
\mathrm{E}=1.22+0.06 \mathrm{~S}
$$

Where $\mathrm{E}$ is the distribution width and $\mathrm{S}$ is the effective span length. In all cases, the effective width has not to increase $2.134 \mathrm{~m}$.

This width is effective in carrying loads of the bridge. In the AASHTO procedure, this width is calculated over which half of the truckload is assumed to be uniformly distributed.
AASHTO presented another approach for the load distribution by considering more parameters based on the Load and Resistance Factor Design (LRFD), such as bridge width and the number of lanes. So, the LRFD suggested an equivalent width of longitudinal strip per lane for more than one lane and is determined as:

$$
\mathrm{E}=2.1+0.12 * \sqrt{\left(\mathrm{L}_{1} \mathrm{~W}_{1}\right)} \leq \frac{\mathrm{W}}{\mathrm{N}_{\mathrm{L}}}
$$

Where $\mathrm{E}$ is the slab equivalent width over which two lines of the truckload wheels is assumed to be uniformly distributed, $\mathrm{L}_{1}$ is the modified span length taken equal to the lesser of the actual span or $18 \mathrm{~m}, \mathrm{~W}_{1}$ is the modified edge-to-edge width of the bridge taken equal to the lesser of the actual width or $18 \mathrm{~m}, \mathrm{~W}$ is the physical edge-to-edge width of the bridge and $\mathrm{N}_{\mathrm{L}}$ is the number of design lanes.

Amer, A. et al (1999) conducted a theoretical and field investigation to calculate the effective width of slab deck bridges. They proposed a simplified equation of the effective width and compared that width with an existing code of specifications as shown in equations (6-8).

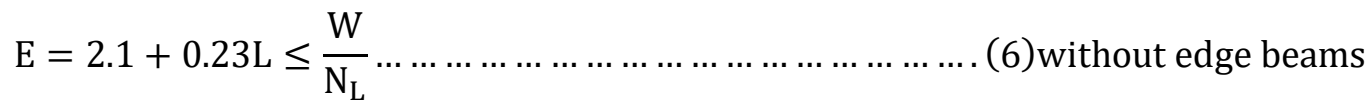

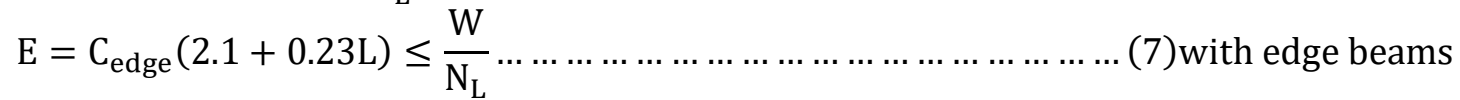

$$
\begin{aligned}
& \mathrm{C}_{\text {edge }}=1+0.5\left(\mathrm{~d}_{1}-0.15\right) \geq 1
\end{aligned}
$$

Where: $\mathrm{E}=$ =effective width, $\mathrm{L}=$ span length, $\mathrm{W}=$ bridge width and $\mathrm{N}_{\mathrm{L}}=$ number of lanes and $\mathrm{d}_{1}$ is the edge beam depth above the slab thickness.

The study was conducted for bridges with and without edge beams. They also studied various parameters that affect the effective width by conducting a parametric study. They concluded that both the span length and the edge beam depth are the main parameters that affect the effective width.

Chen et al. (2007) implemented a numerical analysis based on the finite element to find the effective slab width. The effective width was calculated by dividing the total slab compressive force to the force per unit width or the trapezoidal area of the stress block. They divided the method to effective width on the Positive Moment Section and the Negative Moment Section to differentiate between the stresses at each section to be used in specific equations.

Later studies by Moustafa and Mosalam (2016) explained experimentally a procedure for determining the effective width based on the equivalent strain block concept. The strain distribution was obtained by distributing many strain gauges around the load. Then, the area under the strain distribution was calculated and transformed to an equivalent strain block with a 
width equals an effective width corresponding to the minimum strain reading.

\section{The objectives of this study are:}

1. Identify the main parameters that affect the effective width of slab deck bridges using the finite element method.

2. Compare the effective width resulted from this study to that mentioned in standards like AASHTO and LRFD.

3. Propose a simplified design formula for the effective width that would give more accuracy in determining the effective with than those mentioned in the current standards of design.

\section{METHOD OF ANALYSIS}

This study uses the finite element method to study the various parameters that affect the slab deck bridge effective width calculations and to propose the main parameters that have to be taken into consideration in the evaluation.

\section{Finite element modelling of the analysed slab}

In order to simulate the structural response of the tested slab Deck Bridge, the finite element software ABAQUS (ABAQUS theory manual 2013) was used in this study. Since the bridge was symmetric in both loading and boundary conditions, a suggestion was conducted to model a quarter of the slab Deck Bridge. In the modelling of concrete, 8 node 3D continuum elements with reduced integration [C3D8R] were chosen to avoid the shear locking (Abdulrahman et al 2017). As known, the concrete failure modes are cracking in tension and crushing in compression. So, the concrete behaviour was modelled by the Concrete
Damage Plasticity Model which can give suitable and reasonable results for the numerical simulation of the 3D state of stress (Winkler and Stangenberg 2008, Grassl and Jirasek 2006). The concrete material properties that are presented in the finite element simulation are the modulus of elasticity $E_{0}$, the Poisson's ratio $v$ and the compressive and tensile strengths. The Poisson's ratio, $v$, is considered constant in the concrete damage plasticity model even for cracked concrete (Genikomsou and Polak 2015). Therefore, the value of $v$ of 0.2 was assumed in this study. The stress-strain relationship described by Eurocode 2 [Eurocode 2004] was used to model the compression behaviour of the concrete, while the tensile behaviour was modelled by the exponential relationship between the tensile stresses and the concrete crack width described by the equation of Cornelissen et al. (1986). The slab deck bridge was designed based on the Iraqi standards to find the suitable reinforcement amount. Then, the reinforcement was modelled by using 2-node truss elements [T3D2] as an elastic-plastic material. The reinforcement mesh was embedded through the concrete elements with a full bond between the two. Restraints were also introduced at the bottom edges of the slab deck bridge in the direction of the applied load. Figure 2 gives details of the geometry and the boundary conditions that were used for the simulations. In the modelling of loading, one Iraqi military tracked load was positioned in the mid-span of the bridge in which its centre coincides with the bridge centre to obtain the maximum moment. 


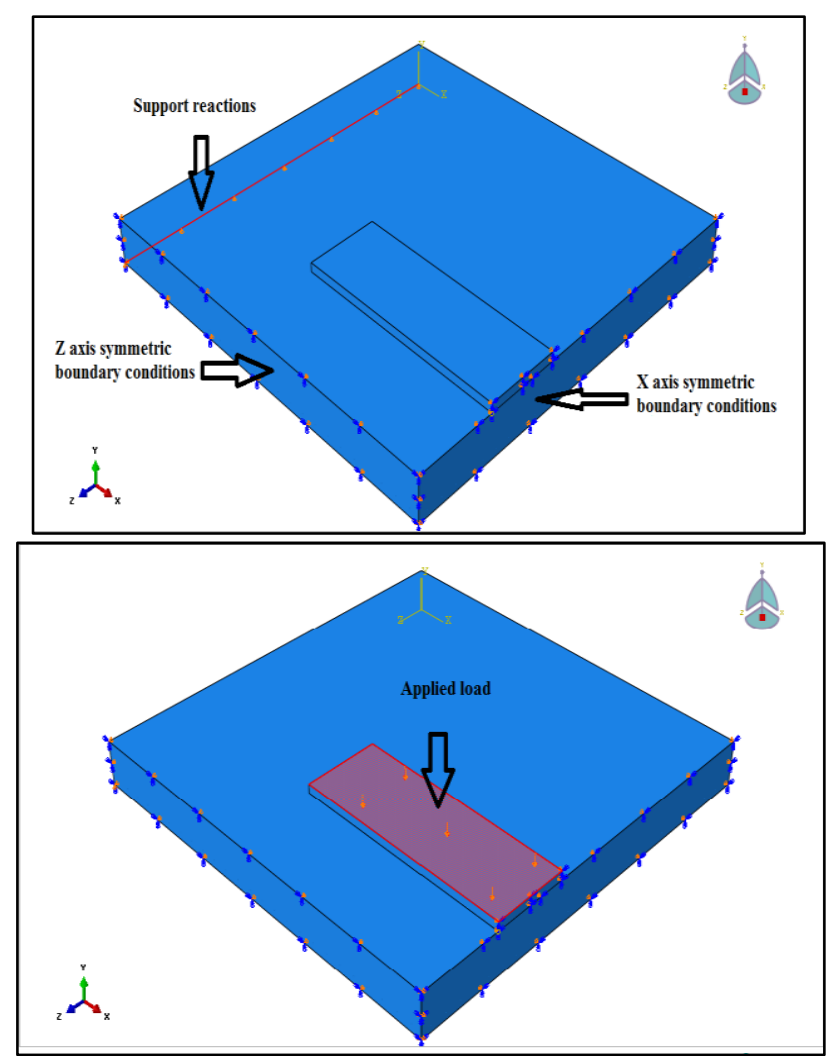

Fig. (2): Geometry boundary conditions, supports and load applied on the slab deck bridge

\section{Determination of Effective Width (Be):}

The structural behaviour of reinforced concrete slab deck bridges is affected by the effective width that shares the resisting of the applied loading in addition to the end rotational restraint that could be offered by the slab abutment (Eitel et al 2002). An effective width is the width of an imaginary rectangular strip across which the loads are considered to be uniformly distributed (Amer et al 1999, Dunham, C. W 1964, Ferguson et al 1988). This width is calculated from the distribution of the moments determined from the finite element analysis as the ratio of the sum of the moments, or the total area under the moment distribution curve, to the maximum moment (Amer et al 1999).

$$
\mathrm{B}_{\mathrm{e}}=\frac{\Sigma \mathrm{M}}{\mathrm{M}_{\max }}
$$

To get more understanding, Figure 3 gives the transverse distribution of the longitudinal moments at two different transverse sections in a slab deck bridge under a central point load. 


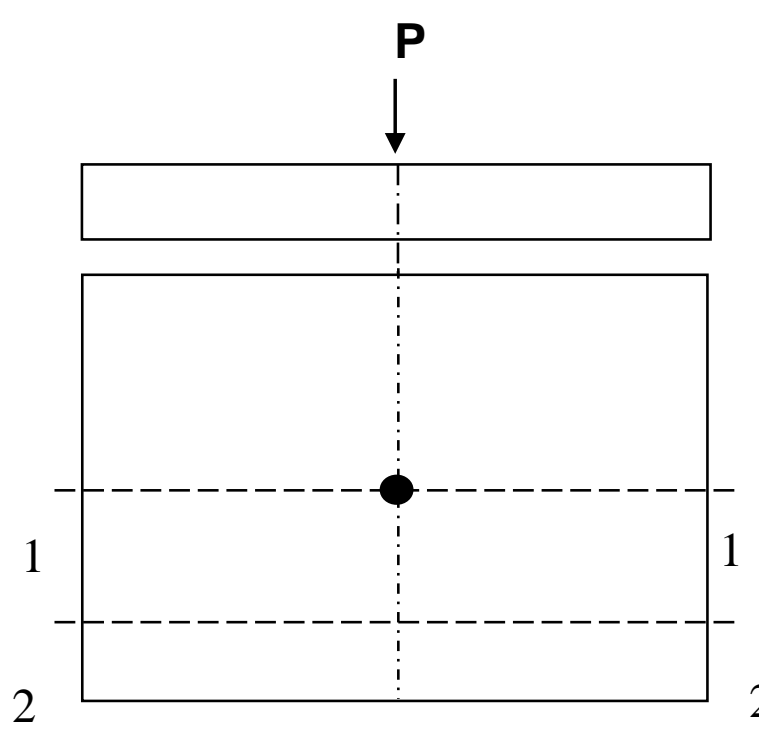

Fig. (3): Distribution of Moments in Bridge Cross Section
When the total longitudinal moments (area under the curve shown in the Figure 3 ) at section 1-1 and 2-2 are $M_{1}$ and $M_{2}$ respectively, and the maximum longitudinal moments at these two sections are assigned as $\mathrm{M}_{\mathrm{x} 1}$ and $\mathrm{M}_{\mathrm{x} 2}$ respectively, then the effective width at section 1-1 will be the total longitudinal moment $\mathrm{M}_{1}$ divided by the maximum longitudinal moment $M_{x 1}$, the same procedure is to be used to find the effective width at section 2-2.

The transverse distribution of the longitudinal moments depends on the location of the loading. Different effective widths along the slab length can be obtained from different loading locations. But, when the effective width value in a specific location is known, the maximum moment and shear in the unit width of the slab deck bridge can be calculated as a fraction of $\left(1 / B_{e}\right)$ of the bending moment and shear due to any loading case.

For the Iraqi military tracked load, the effective width calculated from the distribution of the moment at cross-section must not exceed the bridge actual width. Furthermore, in the case of loading near the unsupported edge of the slab deck bridge, the effective width must neither exceed the bridge actual width nor half the bridge plus the distance of the load from the unsupported edge as shown in Figure 4 (Aswani et al 2004).

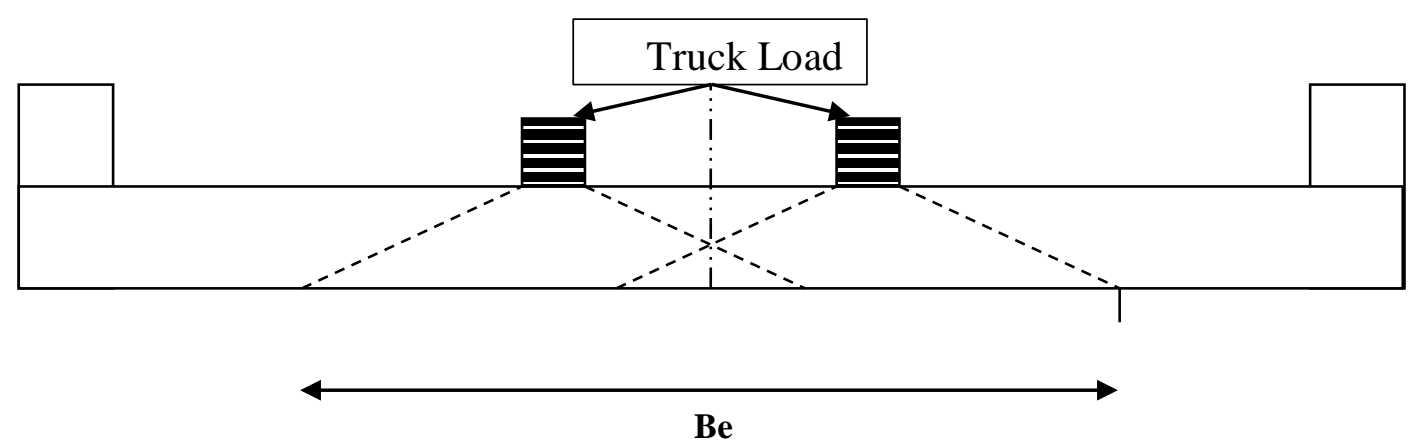

Fig. (4): Slab Bridge under Tank Load (Aswani et al 2004)

bassam.qasim@spu.edu.iq

${ }^{1}$ Corresponding author: Darbandikhan Technical Institute, Al-Sulaymania 


\section{Limited parametric study}

Amer et al (1999) implemented a parametric study to determine the main parameters that affecting the slab deck bridge effective width. They stated that longer spans bridges have a more uniform moment distribution, i.e., larger effective width. Furthermore, they also concluded that the variation in the slab thickness has only very little effect in the effective width. So, it can be neglected.

The main purpose of conducting this parametric study is to develop a sufficient basis for a simplified accurate design equation of computing effective width. To achieve simplicity without losing accuracy, the proposed procedure is limited as follows:

1- Support conditions: The support condition used in this study is simply supported at the two opposite ends of the bridge.
2- Aspect ratio: The aspect ratio represents the ratio of bridge width to length and it is limited to $1,0.9,0.8,0.7,0.6$, and 0.5 to cover the most dimensions of bridges. Other dimensions can be interpolated based on the above ratios.

3- Existence of edge beams: Half of the slabs are analysed without edge beams and the others are analysed with edge beams.

4- Loads: The loads used in the analysis are limited to the tank load [class 100 of Iraq specifications (Iraqi standard Specification 1978) with a weight of 90 tonnes] as in Figure 5. The tank is located to give the maximum bending moment in the slab where its centre coincides with the bridge centre.

5- Finally, the slab thickness is limited to $5 \%$ of the total span length.
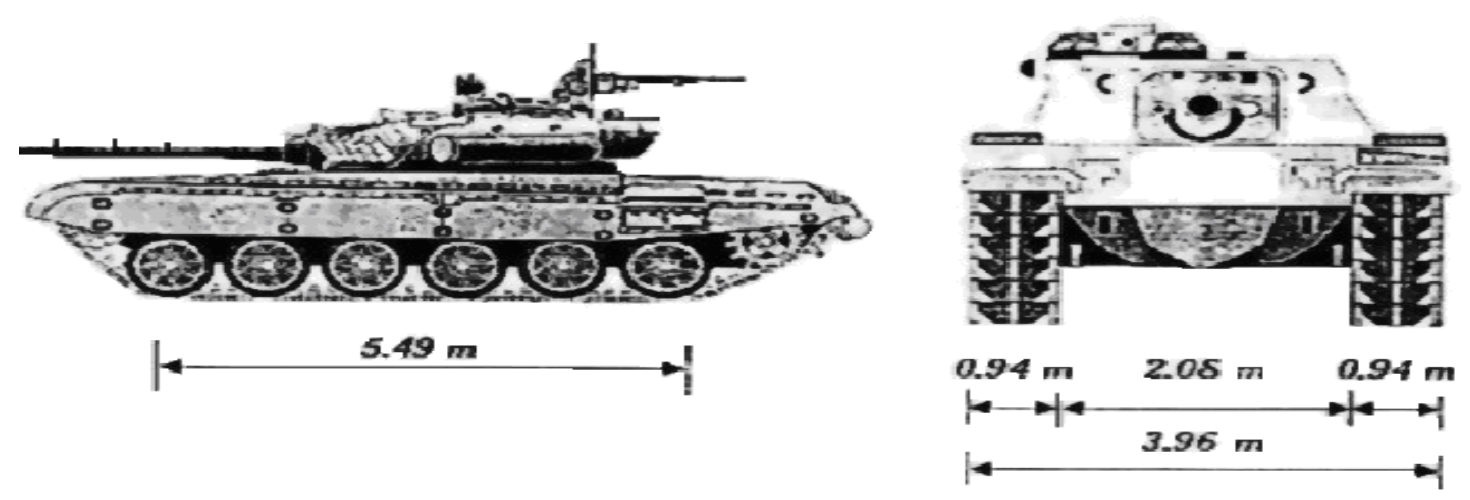

Fig. (5): Tracked Vehicle (Class 100) of Iraq Specifications (Iraqi standard Specification 1978)

A total of 24 analysis cases were considered for the analysis, considering the whole previous mentioned limitations.

The AASHTO code specification (AASHTO 2017) requires that an edge beam should be provided for slabs those reinforcements are longitudinally (main reinforcements are parallel to the traffic). Slab bridges will be more efficient to carry and distribute loads if an edge stiffening beam is to be used. The edge beam could be as following:

1- A slab section with additional reinforcement.
2- A beam integrally connected to the slab but with a deeper section.

3- A reinforced section of the slab integral with the curb (Amer et al 1999)

For slab bridges with a span of $10 \mathrm{~m}$, the specifications of the edge beam are used as in Figure (6-a), and for slab bridges with spans of $20 \mathrm{~m}$, the specifications of edge beam are used as in

Figure

(6-b). 

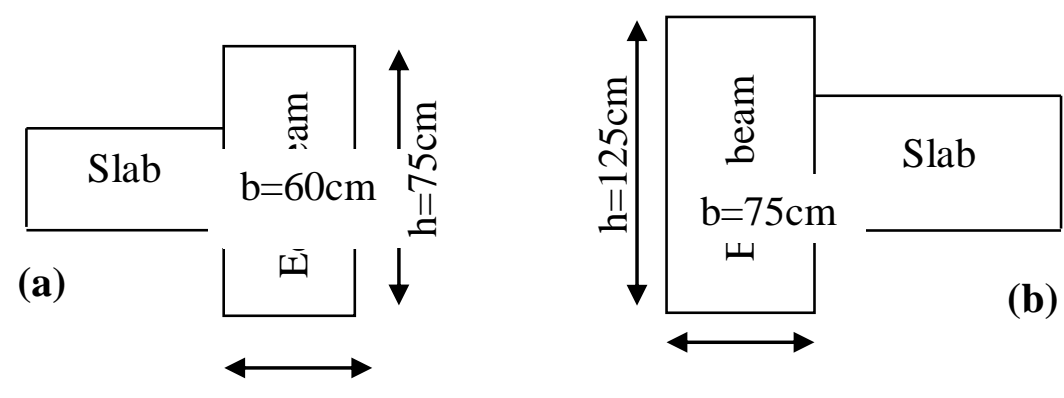

Fig. (6): specifications of the edge beam used in the analysis

\section{RESULTS AND DISCUSSION}

Each slab deck bridge was modelled and analysed in ABAQUS to find the total longitudinal moments in each section. The values of the longitudinal moments are calculated longitudinally in transverse sections along the whole span of the bridge.

In each cross-section, the effective width was calculated by using equation (9) in which the summation of the whole moments in each section was calculated by using Simpson's Rule.
Figure 7 shows the effective width along the whole span of the bridge when a tracked load was located centrally with the slab deck bridge centre. With the increased use of very fast computers in the engineering fields, more equations were derived or even solved in a small time. Thus, by doing a curve fitting to the curve, an equation of the effective width can be extracted as explained in equation (10), in which $x$ represents the distance along the slab deck bridge from the first support to the second support. This equation has a correlation coefficient of 1 , standard deviation of $0.08 \%$ and coefficient of variation of $0.91 \%$ :

$$
\begin{gathered}
B_{\text {eff }}=-0.000182 x^{6}+0.005462 x^{5}-0.064316 x^{4}+0.376003 x^{3}-1.121434 x^{2}+1.517050 x \\
+8.2206 .(10)
\end{gathered}
$$

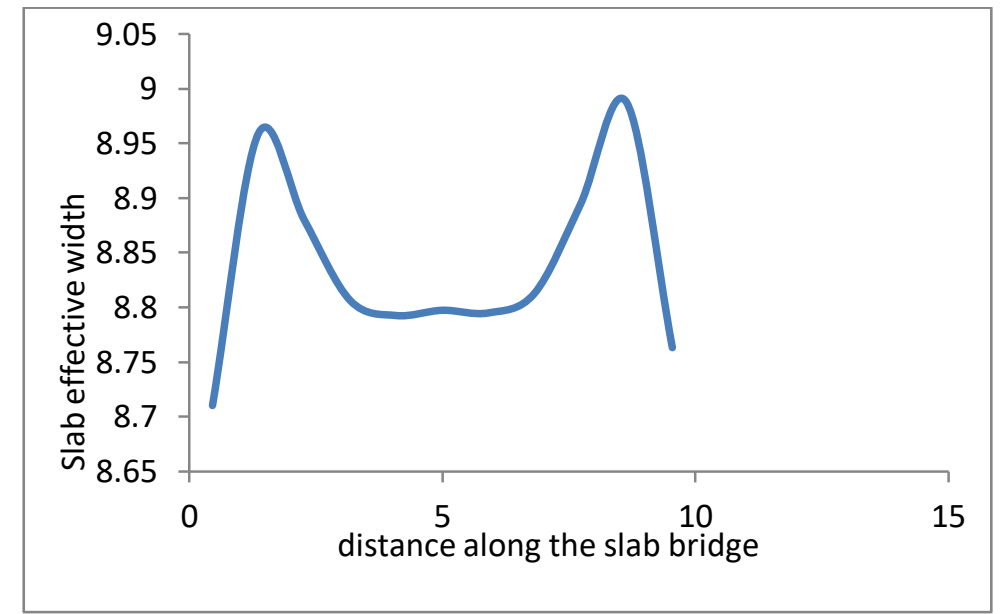

Fig. (7): Effective width for Slab Bridge under Tracked Load

This equation was derived for a typical slab deck bridge of $(10 \times 10) \mathrm{m}$ in length and width respectively. But for any other slabs, they all have the same trend of the effective width as it was also noticed by Jain, H.K
(2018) and Abdulrahman, B. Q. (2007). So, the effective width along the span of slab Deck Bridge can be calculated by multiplying the effective width of the typical slab deck bridge by a distribution

bassam.qasim@spu.edu.iq

${ }^{1}$ Corresponding author: Darbandikhan Technical Institute, Al-Sulaymania 
factor. The distribution factor was calculated from dividing the average effective width of the required slab Deck
Bridge to that calculated in the typical slab deck bridge and summarized in table 3 below:

Table (3): Distribution Factor $\left(\mathrm{K}_{0}\right)$ of this study for the Tracked Vehicle of Iraq specifications

\begin{tabular}{cccccc}
\hline No. & $\mathbf{B} / \mathbf{L}$ & $\begin{array}{c}\text { Span=10 } \mathbf{m} \\
\text { Without edge beam }\end{array}$ & $\begin{array}{c}\text { Span=20 } \mathbf{~} \\
\text { Without edge beam }\end{array}$ & $\begin{array}{c}\text { Span=10 } \mathbf{~} \\
\text { With edge beam }\end{array}$ & $\begin{array}{c}\text { Span=20 } \mathbf{~} \\
\text { With edge beam }\end{array}$ \\
\cline { 2 - 6 } & 1 & $\mathrm{~K}_{0}$ & $\mathrm{~K}_{0}$ & $\mathrm{~K}_{0}$ & $\mathrm{~K}_{0}$ \\
\hline 1 & 1 & 2.8273 & 0.88 & 2.7703 \\
\hline 2 & 0.9 & 0.7863 & 2.515 & 0.721 & 2.4741 \\
\hline 3 & 0.8 & 0.6644 & 2.1572 & 0.581 & 2.144 \\
\hline 4 & 0.7 & 0.4 & 1.7862 & 0.3919 & 1.7792 \\
\hline 5 & 0.6 & 0.2232 & 1.3898 & 0.2332 & 1.3956 \\
\hline 6 & 0.5 & 0.2093 & 1.0017 & 0.0028 & 1.0054 \\
\hline
\end{tabular}

A comparison was conducted between the effective width of this study and the effective width of other codes like (AASHTO, LRFD specifications) for slabs without edge beams because all other codes do not take the edge beams in the calculations of the effective width as in table 4:

Table (4): Comparison of Tracked load effective width with (AASHTO, LRFD) specifications

\begin{tabular}{|c|c|c|c|c|c|c|c|c|}
\hline No. & $B / L$ & $\begin{array}{l}\mathrm{L} \\
(\mathrm{m})\end{array}$ & $\begin{array}{l}B \\
(m)\end{array}$ & $\begin{array}{l}\text { AASHTO } \\
\text { (Be) }\end{array}$ & $\begin{array}{l}\text { LRFD } \\
\text { (Be) }\end{array}$ & $\begin{array}{l}\text { Present work } \\
\text { (Be) }\end{array}$ & 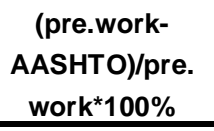 & $\begin{array}{c}\text { (pre. work-LRFD)/pre. } \\
\text { work }^{*} 100 \%\end{array}$ \\
\hline 1 & 0.5 & 10 & 5 & 3.64 & 5.897 & 1.841 & -97 & -220 \\
\hline 2 & 0.6 & 10 & 6 & 3.64 & 6.059 & 1.963 & -85 & -208 \\
\hline 3 & 0.7 & 10 & 7 & 3.64 & 6.207 & 3.519 & -3 & -76 \\
\hline 4 & 0.8 & 10 & 8 & 3.64 & 6.346 & 5.845 & 37 & -8 \\
\hline 5 & 0.9 & 10 & 9 & 3.64 & 6.476 & 6.917 & 47 & 6 \\
\hline 6 & 1 & 10 & 10 & 3.64 & 6.6 & 8.797 & 58 & 25 \\
\hline 7 & 0.5 & 20 & 10 & 4.84 & 7.594 & 8.304 & 41 & 8 \\
\hline 8 & 0.6 & 20 & 12 & 4.84 & 7.918 & 11.522 & 57 & 31 \\
\hline 9 & 0.7 & 20 & 14 & 4.84 & 8.215 & 14.808 & 67 & 44 \\
\hline 10 & 0.8 & 20 & 16 & 4.84 & 8.493 & 17.884 & 72 & 52 \\
\hline 11 & 0.9 & 20 & 18 & 4.84 & 8.753 & 20.851 & 76 & 58 \\
\hline 12 & 1 & 20 & 20 & 4.84 & 9 & 23.440 & 79 & 61 \\
\hline
\end{tabular}

For small spans of slab deck bridges, this method gives effective width close to the effective width of other methods. But, for long spans, it gives higher effective width compared to other methods. An explanation for that is, other methods have a limited value of effective width and the calculated effective width has not to be more than this value. Furthermore, these methods do not take into consideration all the parameters required in the calculation of the effective width like the edge beams. 


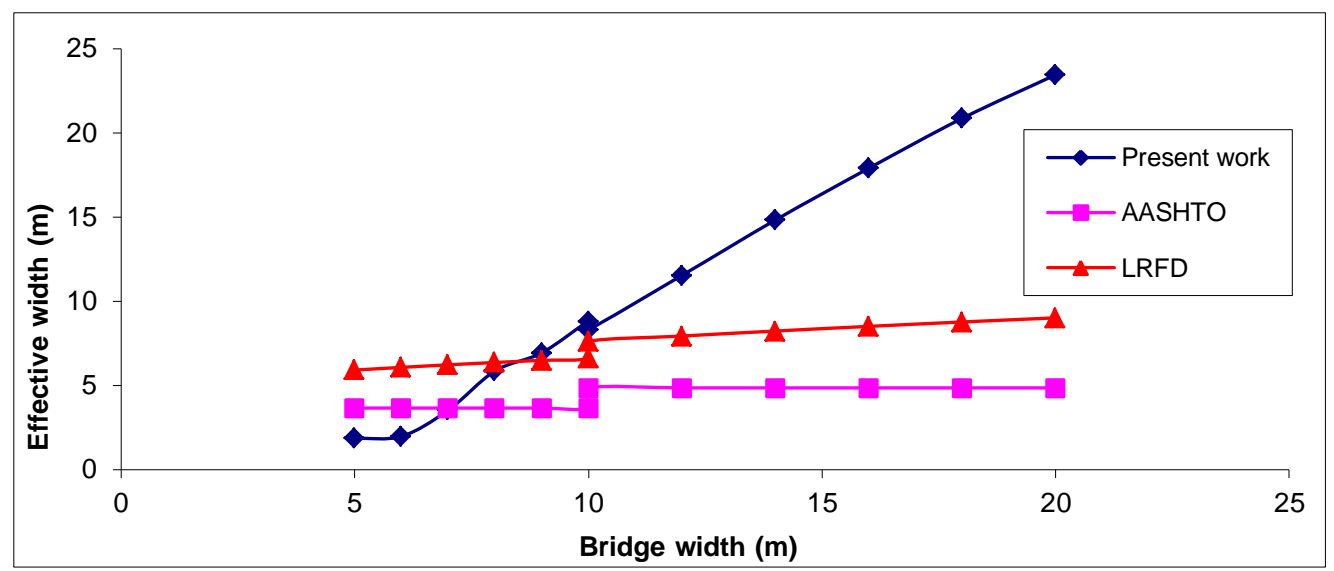

Fig. (8): Comparison of present work with AASHTO and LRFD Specifications

It is noticed that this method differs from the AASHTO method by (-97 to 79)\% while differs from LRFD method by (-220 to 61)\%. This difference is due to the limitation of these methods in calculating the effective width that make it the same for most of the slab bridges lengths.

By applying this method to slabs with edge beams, it is noticed that the effective width is affected by the edge beam. Slabs with edge beams have smaller effective width than slabs without edge beams as it is clear from the distribution factor $\left(\mathrm{K}_{0}\right)$ presented in table 3 for slabs with edge beams.

\section{CONCLUSIONS}

This study was conducted to give more understanding of the distribution of the Iraqi military tracked load on slab deck bridges. The following conclusions were extracted:

1. The minimum effective slab width takes place below the applied load and then increases away from the load centre.

2. The method gives some conservative results in comparison with AASHTO and LRFD standards because other standards have some limitations in addition to not taking into consideration all the parameters required.

3. Effective width is affected by the existence of edge beam; hence slab bridges with edge beams at the sides have an effective width smaller than that without because the increasing of edge moment causes decreasing in slab moment and decreasing in the effective width as mentioned by Amer et al.
4. Effective width is affected by the span length. So, for the same aspect ratio $(\mathrm{B} / \mathrm{L})$, slab bridges with large spans have an effective width greater than that of smaller spans.

\section{REFERENCES}

AASHTO LRFD Bridge Design Specifications, 2017, American Association of State Highway and Transportation Officials (AASHTO), Eighth Edition, Washington, D.C.

ABAQUS, Theory Manual, User Manual and Example Manual, Version 6.12, Dassault Systemes Simulia Corp., Providence, 2013.

Abdulrahman, B. Q. 2007. Analysis of slab bridges under Iraqi military tracked load. M.Sc. thesis, University of Baghdad, Iraq.

Abdulrahman, B.Q., Wu, Z. and Cunningham, L.S., 2017. Experimental and numerical investigation into strengthening flat slabs at corner columns with externally bonded CFRP. Construction and Building Materials, 139, pp.132-147.

Amer, A., Arockiasamy, M. and Shahawy, M., 1999. Load distribution of existing solid slab bridges based on field tests. Journal of Bridge Engineering, 4(3), pp.189-193.

Aswani, M.G., Vazirani, V.N. and Ratwani, M.M., 2004. Design of concrete bridges. Khanna Publishers.

Chen, S.S., Aref, A.J., Chiewanichakorn, M. and Ahn, I.S., 2007. Proposed effective width criteria for composite bridge girders. Journal of bridge engineering, 12(3), pp.325-338.

Cornelissen, H.A.W., Hordijk, D.A. and Reinhardt, H., 1986. Experimental determination of crack softening characteristics of normal weight and lightweight. Heron, 31(2), pp.45-56.

Deng, P. and Matsumoto, T., 2018. Determination of dominant degradation mechanisms of RC

bassam.qasim@spu.edu.iq

${ }^{1}$ Corresponding author: Darbandikhan Technical Institute, Al-Sulaymania 
bridge deck slabs under cyclic moving loads. International Journal of Fatigue, 112, pp.328-340.

DIN 1045-2:2008 Tragwerke aus Beton, Stahlbeton und Spannbeton - Teil 2: Beton - Festlegung, Eigenschaften, Herstellung und Konformität Anwendungsregeln zu DIN EN 206-1

Drar, A.A.M. and Matsumoto, T., 2016. Fatigue analysis of RC slabs reinforced with plain bars based on the bridging stress degradation concept. Journal of Advanced Concrete Technology, 14(1), pp.21-34.

Dunham, C. W., 1964. Advanced Reinforced Concrete, McGraw- Hill, USA.

Eitel, A., Huckelbridge, A. and Capaldi, N., 2002. Development of a Load Test for the Evaluation and Rating of Short-Span Reinforced Concrete Slab Bridges (No. FHWA/OH-2002/012,).

European Committee for Standardization. (2004). EN 1992-1-1Eurocode 2: Design of concrete structures - Part 1-1: General rules and rules for buildings.

Ferguson, P.M., Breen, J.E. and Jirsa, J.O., 1988. Reinforced concrete fundamentals.

Genikomsou, A.S. and Polak, M.A., 2015. Finite element analysis of punching shear of concrete slabs using damaged plasticity model in ABAQUS. Engineering Structures, 98, pp.3848.

Goldbeck, A. T., 1917, "The influence of total width on the effective width of reinforced concrete slabs subjected to central concentrated loading." ACI Journal Proceedings, Vol. 13, No. 2, pp. 78-88.

Goldbeck, A. T., Smith, E. B., 1916, "Tests of large reinforced concrete slabs." ACI Journal Proceedings, Vol. 12, No. 2, pp. 324-333.

Grassl, P. and Jirasek, M. 2006. Damage-plastic model for concrete failure. International journal of solids and structures, 43(22), pp.7166-7196.

Indian Road Congress IRC: SP: 13, 2013. Guidelines for the design of small bridges and culverts.
New Delhi: Published by Indian Roads Congress.

Iraqi standard Specification for Road Bridges (Loadings), Baghdad, 1978.

Jain, H.K., 2018. Computer-Aided Analysis of Fixed Arch for IRC Loading.

Johansen, K.W., 1932. Moments of rupture in crossreinforced slabs. Proc. Intern. Assoc. Bridge and Structural Eng, 1, pp.277-296.

Motarjemi, D. and Van Horn, D.A., 1969. Theoretical analysis of load distribution in prestressed concrete box-beam bridges. Fritz Engineering Laboratory, Department of Civil Engineering, Lehigh University.

Moustafa, M.A. and Mosalam, K.M., 2016. Effective Width of Integral Bent Caps in ReinforcedConcrete Box-Girder Bridges. In Geotechnical and Structural Engineering Congress 2016 (pp. 77-89).

Slater, W. A, Hagener, A. and Anthes, G. P., 1923.Test of a Hollow Tile and Concrete Floor Slab Reinforced in Two Directions, 1I Technologic. Papers of the Bureau of Standards, Vol. 16, pp. 727 -796.

Stanton, J.F., 1987. Proposed design rules for load distribution in precast concrete decks. Structural Journal, 84(5), pp.371-382.

Warren, G. and Malvar, L.J., 1993. Lateral Distribution of Loads in One-Way Continuous Navy Pier Decks. Journal of Structural Engineering, 119(8), pp.2332-2348.

Westergaard, H.M., 1930. Computation of stresses in bridge slabs due to wheel loads. Public Roads, 11(1), pp.1-23.

Westergaard, H.M. and Slater, W.A., 1921, February. Moments and stresses in slabs. In Journal Proceedings (Vol. 17, No. 2, pp. 415-538).

Winkler, K. and Stangenberg, F. (2008). Numerical Analysis of Punching Shear Failure of Reinforced Concrete Slabs. ABAQUS User.s Conference, Newport, RI. Dassault Systemes, USA, Lowell,

MA. 